Ramos Ahijado, S. \& Botella Nicolás, A.M. (2016). La integración del videojuego educativo con el folklore. Una propuesta de aplicación en educación primaria. Revista Electrónica Interuniversitaria de Formación del Profesorado, 19(3), 115-121.

DOI: http://dx.doi.org/10.6018/reifop.19.3.267281

\title{
La integración del videojuego educativo con el folklore. Una propuesta de aplicación en Educación Primaria
}

\author{
Sonsoles Ramos Ahijado1, Ana María Botella Nicolás² \\ ${ }^{1}$ Universidad de Salamanca, ${ }^{2}$ Universitat de València
}

\section{Resumen}

El artículo se centra en una experiencia de innovación en Educación Primaria que forma parte del trabajo práctico de la asignatura Música y nuevas tecnologías del Grado en maestro de Educación Primaria impartida en la Escuela Universitaria de Educación y Turismo de Ávila (Universidad de Salamanca), enmarcada en el programa Prácticas de campo. Modalidad II (2015/2016_OP4) del Campus de Excelencia Internacional Studii Salamantini. Consiste en la aplicación del videojuego La granja musical a 46 alumnos de primero y segundo de Educación Primaria del CEIP Santa Ana de Ávila con la finalidad de recuperar la tradición popular del pasado, interpretarla en el presente y proyectarla hacia las nuevas generaciones del futuro, para familiarizar a los alumnos con sus raíces folklóricas. Los resultados demuestran un alto grado de consecución de los objetivos planteados, junto con una participación significativa de elementos innovadores, tanto en la vertiente de las estrategias didácticas como en la relativa a los recursos tecnológicos empleados.

\section{Palabras clave}

Videojuego; folklore; Educación Primaria

Contacto

Ana María Botella Nicolás, ana.maria.botella@uv.es, Departamento de Didáctica de la Expresión Musical, Plástica y Corporal. Facultad de Magisterio (Universitat de València). Campus de Tarongers. Avda./Tarongers, 4, 46022 . 


\title{
Integration of educational videogame and folklor. A proposal for its application in First Education
}

\begin{abstract}
The article focuses an innovating experience in primary education part of the subject Music and new Technologies in the degree of Primary School Education in the Escuela Universitaria de Educación y Turismo de Ávila (Universidad de Salamanca). This experience is a practical work of the programme Prácticas de campo. Modalidad II (2015/2016_OP4) that belongs to the Campus of International Excellence Studii Salamantini. The Project deals with the use of a videogame (La Granja Musical) by 46 pupils of the first and second year of Primary school (at the CEIP Santa Ana de Ávila) with the aim of recovering the popular tradition of the past, reinterpreting it at the present and projecting it to the future, in order to connect these pupils with their folkloric roots. The results show a high degree of achievement of the goals and an important set of innovating elements, both in the didactic strategies and those related to the used technological resources.
\end{abstract}

\section{Key words}

Videogame; folklor; First Education

\section{Introducción}

La experiencia de innovación que se presenta forma parte del trabajo práctico de la asignatura Música y nuevas tecnologías del Grado en maestro de Educación Primaria impartida en la Escuela Universitaria de Educación y Turismo de Ávila (Universidad de Salamanca), enmarcada en el programa Prácticas de campo. Modalidad II (2015/2016_OP4) del Campus de Excelencia Internacional Studii Salamantini. Consiste en la aplicación del videojuego La granja musical a 46 alumnos de primero y segundo de Educación Primaria del CEIP Santa Ana de Ávila.

Los videojuegos son recursos lúdicos y divertidos, que estimulan al usuario desde el principio (Pindado, 2005). Los videojuegos, sin perder este carácter motivador y atractivo, permiten al docente usarlos como un arma importante para transmitir conocimientos. Desarrollan capacidades verbales, de atención y memoria, espacio-visuales, de relación y trabajo colaborativo y de superación (Marín y García, 2006). Además, refuerzan la autoestima de los jugadores, aumentando ésta cada vez que se alcanza algún objetivo y premian su esfuerzo (Gómez, 2007). Y, por último, favorecen el desarrollo de diferentes destrezas y habilidades psicomotrices, de comprensión, de toma de decisiones, de resolución de conflictos, cognitivas o académicas, entre otras muchas (Gros, 2004).

En la actualidad, los videojuegos han sufrido cambios significativos gracias a la evolución de la tecnología ya que la mayoría de usuarios de videojuegos espera un aspecto funcional de ellos. $\mathrm{Y}$ es aquí donde a los docentes se nos abre un futuro esperanzador con la introducción de las tabletas y los móviles en el aula, junto a la creciente demanda de videojuegos a través de estos dispositivos. Además, una de las principales preocupaciones de los profesores de música es cómo enseñar al alumnado a saber disfrutar y escuchar la música, ya que habitualmente suelen tener dificultades, especialmente cuando escuchan el repertorio musical occidental (Ramos y Botella, 2016). 
Por otra parte, el respeto y la valoración del folklore propio de cada Comunidad, así como el reconocimiento de la riqueza del patrimonio cultural es una constante en la Ley Orgánica 8/2013, de 9 de diciembre, para la mejora de la calidad educativa (LOMCE), y en los diferentes Decretos que establecen los contenidos mínimos de la etapa de enseñanza obligatoria y de la asignatura de música. La realidad del aula es otra, ya que no se tiene en cuenta ni se enseña. Los alumnos carecen de conocimientos sobre su propia tierra y las tradiciones de éstas. La música tradicional ha sido durante muchos años uno de los campos más olvidados en el estudio de la música. El folklore y su riqueza constituye un material didáctico interesante, pudiendo así enseñar tanto la historia del sitio donde se reside como la música y las tradiciones más importantes del lugar (Ramos, Botella y Fernández, 2016). Por eso, el principal objetivo del estudio es recuperar la tradición popular del pasado, interpretarla en el presente y proyectarla hacia las nuevas generaciones del futuro, para familiarizar a los alumnos con sus raíces folklóricas.

\section{Objetivos y metodología}

Teniendo presente la normativa vigente por la que se rige el sistema educativo español, la nombrada Ley Orgánica para la Mejora de la Calidad Educativa (LOMCE), y la puesta en práctica del videojuego La granja musical en dos aulas de $1^{\circ}$ y $2^{\circ}$ de Educación Primaria, los objetivos que pretendemos alcanzar son los siguientes:

- Utilizar las nuevas tecnologías de la información y comunicación y, concretamente, los videojuegos en el aula de música de Educación Primaria.

- Iniciar al alumno en la percepción del folklore y la música popular a través de los videojuegos.

- Motivar al alumno, haciéndole partícipe directamente de su propio aprendizaje.

- Fomentar el respeto y la cooperación entre los alumnos, así como el uso responsable y coherente de los videojuegos.

La propuesta integrada por el folklore y los videojuegos educativos arranca con la idea de que el alumno debe jugar y, como consecuencia del juego, aprenderá los contenidos curriculares implícitos en el videojuego.

A continuación se describe el diseño y aplicación del proceso llevado a cabo, junto a los recursos utilizados, desde el punto de vista metodológico:

- $\left.\quad 1^{\mathrm{a}}\right)$ Edición con E-adventure. E-Adventure es un software libre que permite crear videojuegos de aventuras gráficas point and click en entornos seguros y libres facilitando el proceso creativo.

- $\quad 2^{\mathrm{a}}$ ) Determinación del argumento del videojuego La granja musical.

La aventura comienza en la puerta de la granja donde viven los protagonistas Pedro y María, que guiarán al alumno a lo largo de todas las etapas del videojuego. Después, María invita al videojugador para que cante con ella, y le propone un reto musical que consiste en colocar las imágenes y palabras correspondientes de la canción popular Tengo una vaca lechera.

A continuación, Pedro transmite las indicaciones oportunas al jugador para que pueda realizar correctamente la siguiente actividad.

Posteriormente, Pedro habla con el jugador contándole que María está muy triste porque no encuentra los instrumentos musicales de la familia de 
cuerda y, le pide que le ayude a buscarlos para guardarlos en el baúl. María explica al jugador las principales tradiciones culturales de algunas comunidades autónomas: bailes, costumbres, canciones populares e indumentaria, así el alumno realizará la siguiente actividad.

Después, María pide ayuda al jugador para que coloque el nombre de las notas musicales correspondientes en la partitura, y pueda escuchar la canción popular Debajo de un botón.

Finalmente, María y Pedro dan la enhorabuena al jugador porque ha conseguido superar correctamente todas las actividades. Además, todos los animales de la granja le muestran su agradecimiento y se despiden de él cantando.

Recursos: imágenes, audios, fotografías y vídeos (http://recursostic.educacion.es/bancoimagenes/web/).

- $\quad 3^{a}$ ) Creación del videojuego: selección e incorporación de escenas, personajes, objetos de atrezo, actividades musicales, fondos, zonas activas, configuración de salidas y perfil de evaluación. Eadventure consta de un mecanismo de evaluación que genera reportes modificables por personas, que nos servirán para evaluar al alumno, en función de los ítems incluidos anteriormente por el docente.

- $\quad 4^{\mathrm{a}}$ ) Ejecución del videojuego La granja musical.

A lo largo de parte de la jornada lectiva de los días 16 y 17 de noviembre de 2015, concretamente desde las 9:30 hasta las 10:30 horas, los 20 alumnos universitarios organizados en grupos de diez, pusieron en práctica el videojuego La granja musical con los 22 alumnos de primero y 24 de segundo de E.P del CEIP Santa Ana.

\section{Resultados}

Para analizar la viabilidad de la experiencia, hemos utilizado una encuesta de satisfacción a través de la escala psicométrica de Likert, aplicada al final de cada sesión con los alumnos de E.P, siendo representativa del resultado final de la experiencia realizada (Tabla 1):

Tabla 1.

Encuesta

\begin{tabular}{|c|}
\hline $\begin{array}{c}\text { POR FAVOR, VALORA LAS SIGUIENTES AFIRMACIONES } \\
\text { Califica entre } 1 \text { y 5, teniendo presente que: } \\
\text { 1: Totalmente en desacuerdo } \\
\text { 2: En desacuerdo } \\
\text { 3: Ni de acuerdo ni en desacuerdo } \\
\text { 4: De acuerdo } \\
\text { 5: Totalmente de acuerdo }\end{array}$ \\
\hline 1.-Considero que sería capaz de diferenciar una jota de una sevillana \\
\hline $\begin{array}{l}\text { 2.-He aprendido la colocación de las notas en el pentagrama de la canción } \\
\text { Debajo un botón }\end{array}$ \\
\hline 3.-Considero que sabría identificar auditivamente una muñeira \\
\hline
\end{tabular}




\section{4.-Jugando al videojuego La granja musical he recordado la canción popular} La vaca lechera

Como consecuencia de los datos obtenidos, podemos confirmar que la realización de la experiencia docente a través de la práctica de campo, integrada por el folklore y los videojuegos, favorece el aprendizaje eficiente de los alumnos en el ámbito del folklore. El 81.7\% consideran que son capaces de diferenciar una jota de una sevillana. El 69,3\% han aprendido a colocar las notas en el pentagrama de la canción Debajo un botón. Más del $65 \%$ saben identificar a través de la audición una muñeira, y casi un $90 \%$ han recordado la melodía de la canción popular La vaca lechera al jugar al videojuego (Figura 1):

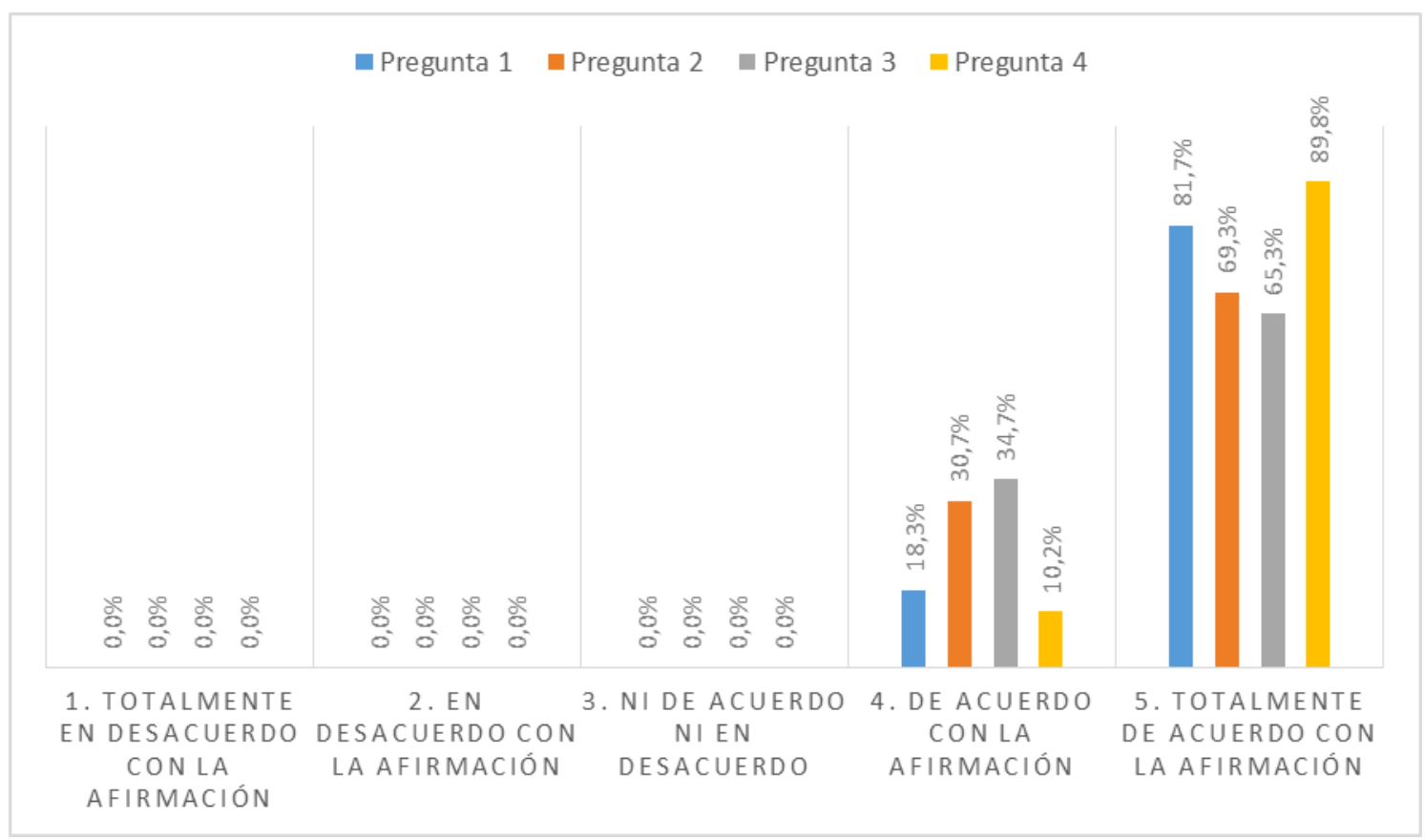

Figura 1. Resultados de la encuesta

En la actualidad, algunas editoriales están incorporando el repertorio popular en los libros escolares desde los primeros niveles educativos para acercar la tradición popular a las nuevas generaciones. Sin embargo, la propuesta de la utilización de músicas tradicionales como material didáctico supone la superación de un modelo educativo donde la música de tradición culta contenía un gran peso en el desarrollo del currículo musical (Costa, 2003).

Por eso, teniendo presente los resultados obtenidos en la presente experiencia, creemos oportuno destacar que los docentes deben despertar el interés en nuestros alumnos para que conozcan el folklore de su país o región.

\section{Discusión y conclusiones}

Los videojuegos son importantes recursos didácticos que se han desaprovechado durante años en el ámbito educativo (Morales, 2009). Éstos actúan como mediadores donde los retos que nos propone el juego ayudan a motivar y divertir, provocando que el aprendizaje sea una consecuencia directa de jugar al juego. Además, el contenido curricular del videojuego lo hemos camuflado bajo los propios elementos del juego para fomentar el éxito del aprendizaje.

La versatilidad de los videojuegos, nos permite otorgarles un gran poder social, formando 
un lenguaje de comunicación: oral, escrito, icónico, musical, numérico y gráfico. Su valor educativo se encuentra en la capacidad para potenciar la curiosidad por aprender favoreciendo determinadas habilidades al permitir el desarrollo de las distintas áreas del currículum (Ramos y Botella, 2016).

Utilizar los videojuegos en el ámbito educativo, implica incluir un espacio subjetivo que posibilita la simulación de roles y actividades simbólicas. Los juegos son escenarios o espacios, que interpretan la vida a través de la variedad de experiencias y posibilidades (Ramos y Botella, 2015).

En definitiva, los videojuegos permiten al alumnado y a los docentes la posibilidad de desarrollar los procesos de enseñanza-aprendizaje desde otra perspectiva, que genera experiencias profundas como la construcción personal, autonomía, y el aprendizaje por descubrimiento.

\section{Referencias bibliográficas}

Costa, L. (2003) "Práctica pedagógica y música tradicional” Revista electrónica de LEEME, 12, 1-7. Recuperado el 3 de marzo de 2016 de, http://musica.rediris.es/leeme/revista/costa03.pdf

Gómez, M. T. (2007). Videojuegos y transmisión de valores. Revista iberoamericana de comunicación, 43, (6), 1-10. Recuperado el 8 de marzo de 2016 de, http://www.rieoei.org/deloslectores/1909 Castillo.pdf

Gros, B. (2004). Pantallas, Juegos y Educación. La alfabetización digital en la escuela. Bilbao: Desclée.

Ley Orgánica 8/2013, de 9 de diciembre, para la mejora de la calidad educativa.

Marín, V.; García, M. D. (2005). Los videojuegos y su capacidad didáctico-formativa. Pixel-Bit: Revista de Medios y Educación, 26, 113-119. Recuperado el 8 de marzo de 2016 de, http://www.sav.us.es/pixelbit/pixelbit/articulos/n26/Revista26.pdf

Morales, E. (2009). El uso de los videojuegos como recurso de aprendizaje en educación primaria y Teoría de la Comunicación. Diálogos de la comunidad, 78, 1-12.

Pindado, J. (2005). Las posibilidades educativas de los videojuegos. Una revisión de los estudios más significativos. Pixel-Bit: Revista de Medios y Educación, 26, 55-67. Recuperado el 8 de marzo de 2016 de, http://www.sav.us.es/pixelbit/pixelbit/articulos/n26/Revista26.pdf

Ramos, S. y Botella, A. M. (2015). Educación musical a través de los videojuegos en la etapa de educación infantil, en Cosme J. Gómez, Tomás Izquierdo (Eds.). Experiencias y recursos de innovación en Educación Infantil. Servicio publicaciones Universidad de Murcia (Edit.um), pp. 109-206.

Ramos, S., y Botella, A. M. (2016). Los videojuegos como herramientas de aprendizaje. una experiencia de innovación con la ópera de Mozart. DEDICA. Revista de Educação e Humanidades, 9, 161-171.

Ramos, S., Botella, A. M. y Fernández, Z. (2016). El folklore de Arenas de San Pedro y su repercusión en la Educación Musical. Propuestas educativas con el audiovisual. Revista de Folklore (en prensa).

Software Eadventure. Recuperado el 3 de marzo de 2016, de http://e-adventure.e-ucm.es/ 
Tutoriales Eadventure. Recuperado el 3 de marzo de 2016, de http://e-adventure.eucm.es/tutorial/

Banco de Imágenes y Sonidos del INTE de Formación del Profesorado. Secretaria de Estado de Educación, Formación Profesional y Universidades (2016). Recuperado el 3 de marzo de 2016, de http://recursostic.educacion.es/bancoimagenes/web/ 